\title{
RAFAEL JOSEFFY'S CONTRIBUTION TO PIANO TECHNIC
}

\author{
By EDWIN HUGHES
}

$\mathrm{T}^{\mathrm{m}}$

HE title of this article does not imply in the least a desire to place one of the most poetic of all pianists in the category of the keyboard mechanicians. Of the grace and finesse of Joseffy's Chopin; the clarity of his Bach, the depth of his Brahms and Beethoven, of the wide catholicity of his taste, resulting in interpretations of Mozart and Liszt, of Schubert and Tschaikowsky that were equally true in conception and beautiful in execution, of all this alone a little volume might be written. Still, the fact remains that his most important legacy to the pianistic world is the work which he accomplished towards making the thorny path of technic more practicable and placing keyboard fluency and freedom a little nearer within reach of the aspiring student.

After he had given up his regular concert appearances, "to give the youngaters a chance," as he humorously put it, his best efforts were directed wholly along the line of advance in technical study. He composed little and his energies were taken up with his lessons, the editing of standard works of pianoforte literature and the compiling of that high-school of the pianist, the "School of Advanced Piano Playing," followed a decade later by his "First Studies," a work of even larger outward proportions. Not that he neglected the interpretative side in all this work, he was far too great an idealist for that-but he wished first and foremost to remove from keyboard stutterers and stammerers those impediments to fluent expression which stood in the way of the untrammeled utterance of what music they had within them.

He was an indefatigable worker at his technical studies and his editions of piano compositions, even during the heated months of the year. The summer visitor who had succeeded after many questionings of the natives in discovering at last the half-overgrown lane which led to Joseffy's secluded retreat in the woods 
of North Tarrytown, and who had scaled the steep, winding ascent to the summit of the hill on which his house was perched, was almost certain to find him seated behind a table full of music and manuscripts on the vine-shaded veranda, in company with the inevitable cigar, poring over some newly-discovered fingering or some ingenious technical figuration. His own practise he kept up quite religiously, except in the summer months, so that he was always in condition to illustrate the most difficult passage at the second piano, or to play in public if need be. The diffidence to public performance in his later years resulted from the growing fear that he might not be able to reach those same heights which he had previously attained with ease. Rather than have it whispered about in the public or blazoned forth in the press that Joseffy's art at the piano was not that of years gone by, he chose to withdraw almost completely from the concert stage, leaving those who had known his playing at its best with an indelible impression on their musical consciousness. Perhaps he was mistaken in his idea, and wrong in depriving music-lovers of some of their most exquisite moments, for the fact is that in later years, when he did occasionally overcome his supersensitiveness so far as to appear at long intervals in public, he was always the object of stormy ovations and his playing seemed to have lost little, if any, of its old charm.

During the years of his retirement from concert-life he devoted a large part of his time to teaching, and the dissemination of his ideas on piano study among the younger generation of American musicians may be looked upon as one of the most important phases of his whole musical activity. Pupils came to him from far and wide, from all parts of the United States as well as from Canada. Teaching he held to be an art, just as much as playing, and therefore he believed in limiting the hours given over to pupils to not more than three each day, or, if the daily period exceeded this time, in confining the teaching to two or three days of the week. His ides was that if lesson-giving went beyond such limits, the teacher could not possibly give his best to the pupil, and that the whole matter sank in consequence from the level of an art to that of a handicraft. The great teacher must also be an equally excellent pianist according to Joseffy's manner of thinking. He must be familiar with the entire pianoforte literature, must be able to illustrate at the second piano everything that he teaches, and must possess such a highly developed analytical faculty that he is able to recognize and impart the all-important "how" in distinction from the "what." 
The mere playing of a piece at the second piano with the remark, "I do it this way," he considered of little help to the pupil, unless the very necessary explanation of the process were also forthcoming.

Such ideals were at the foundation of his work as a teacher. For a certain class of teachers in New York who make a specialty of the fashionable dilettante, charging for lessons a price suitable to the character of their patronage and taking anyone as pupil who is able to pay the stipulated amount, Joseffy had a fine scorn. He himself would have nothing to do with such pupils, and he regarded mere venders of music-lessons as quite unworthy of the respect of the serious musician.

For the real master of the art of teaching, however, he was not backward with his admiration, in spite of his own exalted position as a pedagogue. He often spoke, for example, of Leschetizky as a great teacher, and wondered why he did not write something himself about his pedagogical methods, instead of leaving this matter to others, or why he did not at least give out more or less comprehensive editions of the classics, which would have meant much the same thing to the student. Busoni and Barth he also admired as teachers, while he recognized in d'Albert the complete lack of the pedagogical talent. Although he was very fond of MacDowell personally, he had no great admiration for him as a piano teacher. MacDowell's technical exercises he praised, but considered it a rather remarkable fact that he did not use them to better effect with his own pupils, some of the latter having come to Joseffy unable to play a scale.

Always an enthusiastic champion of Henselt as a composer, whose wane in popularity he attributed to the desire of the present-day public to "always see blood," Joseffy admired greatly this pianist's useful and self-sacrificing pedagogical work as musical inspector of the imperial seminaries for girls in Russia, where, although he did not develop any exceptionally brilliant geniuses, he did incalculable good in raising the general standard of musical education. Although Joseffy was himself a pupil of Liszt in 1870-71, the great Hungarian master was not Joseffy's ideal as a teacher, as he neglected the technical side of piano playing entirely at the lessons. To Tausig, however, Joseffy felt that he owed more than to anyone else. He was his ideal as a pianist-Joseffy rated him higher even than Liszt in this respect -and there can be no doubt that the two impressionable youthful years spent with Tausig gave that mighty artistic impetus to the 
young pianist which carried him to the lofty pinnacle in European musical life a few seasons later.

At his own lessons Joseffy was a great source of inspiration to his pupils. When he felt that he had a responsive intellect at his side, he spared himself no pains in the careful elucidation of his points. His ideas on fingering were illuminating and his methods of practise for overcoming specific technical difficulties in the study matter were quite invaluable. Although he laid great stress on matters of technical detail, he was not to be dazzled by a merely technically brilliant performance. When a new pupil came to him and tried to make an impression with some showy composition he would ask for a Bach Prelude or a Mendelssohn Song without Words. "You may be able to play that technically difficult composition," he would say, "and still not be able to play the piano. From a Bach Prelude or a Mendelssohn Song without Words I can tell right away just how much of a musician you are." Pupils who at the first interview tried to foist upon him an unripe performance of such works as the Appassionata or the $\mathrm{E}$ minor Concerto of Chopin as samples of their pianistic prowess did not usually succeed in earning anything better than his deep disgust.

When he was engaged at one of the New York conservatories, he used to teach in class, having about eight pupils from two to six o'clock in the afternoon. Class work he considered excellent for interpretation, as each pupil is able to hear the others and to gain from criticism, but for technical work he considered it impossible, holding that technic could be properly taught only at private lessons. He believed in giving to less advanced pupils pieces and studies that were within their technical reach, and he was very much put out at an assistant of his who tried to do too much with his pupils by giving them such things as piano arrangements of the Bach organ fugues instead of the Well-Tempered Clavichord, and Chopin Etudes instead of those by Cramer and Clementi, and thus spoiling them for the class work. He was in favor, however, of more advanced pupils trying their mettle on very difficult compositions, even at the risk of failure in the technical mastery of such tasks.

In the selection of works for study Joseffy was very particular in choosing "pieces that help," that is, things that would increase the pupils' technical experience and ability. He considered it rather a waste of time to study pieces that were valuable as studies in interpretation alone, and which would have no bearing on the technical advancement of the pupil. Not, be it said, that he 
wished here to make a musical distinction, but simply that from the standpoint of the student of the instrument he held it to be a more profitable use of time to busy one's self with things that were on the direct highway to a mastery of the technical resources. He certainly would not have placed the first movement of the Schumann Fantasie on a musically lower plane than the opening division of the Chopin B minor Sonata, yet he did not consider the former of any use whatsoever as a study piece, while the latter he ranked very high from this standpoint. Of the Tschaikowsky B flat minor Concerto he said, "After you have studied it, you have learned absolutely nothing but the Tschaikowsky $B$ flat minor, whereas after you have studied the Chopin Concerto you know something more when you are through than merely the works you have been studying." The Scharwenka Staccato Etude was a help on the road to the pianistic Parnassus, while such pieces as the Brahms Intermezzi were of little or no aid to the ambitious scaler of dizzy technical heights.

These ideas in regard to piano study were simply the result of Joseffy's differentiation of virtuoso piano playing and the Kapellmoister sort. He made a sharp distinction between the pianist and the musician who merely plays the piano, and he knew full well that there are many persons of the latter type who could attempt the Brahm's Intermezzi, the Schumann Fantasie and the Tschaikousky $B$ flat minor Concerto and get away with them after a fashion, but to whom the $\mathrm{F}$ minor Concerto of Chopin or the D minor of Mozart would remain a sealed book. "It is curious," he once said, "that people who cannot play the piano can yet play the Grieg Concerto. One has just to know how to play a few chords. That and the Rubinstein D minor anyone can do."

He emphrsized mast strongly the importance of combining technical practise with the study of pieces, his idea being to take the most difficult passages and construct even more difficult technical studies from them. In the invention of such exercises he was an adept. It will suffice to recall one example of his ingenuity in such matters; namely, his exercises on the long octave passage for the right hand in the Schumann Toccata, as they appear in his study edition of that composition. The original, beginning thus

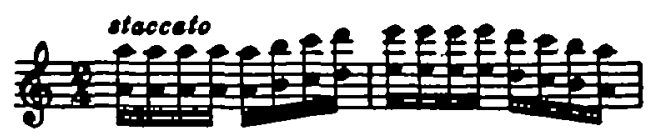



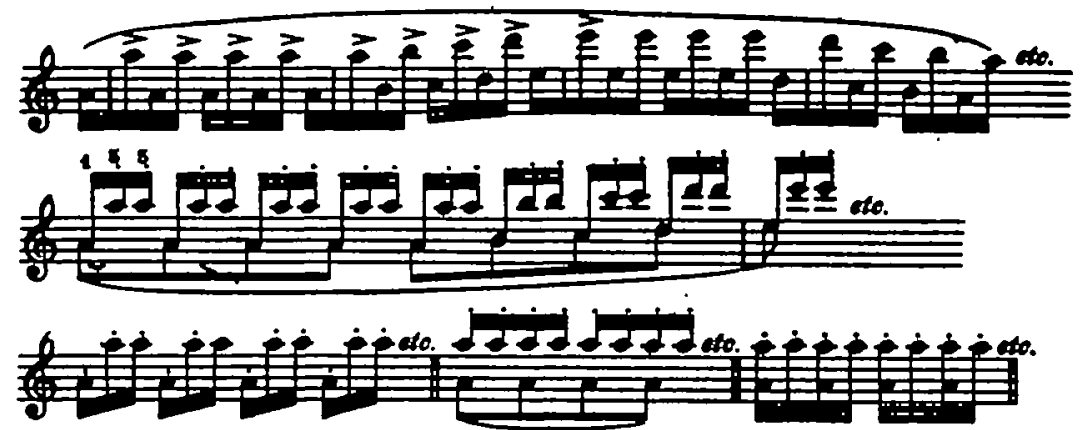

he recommended to be practised as above in several keys, and in the left hand as well as the right. After the study of similar clever variants on this and other difficult passages, the original reading seems mere child's play in comparison.

About the position of the hands at the keyboard he was very particular, requiring a certain roundness in appearance of every part in normal playing position, and in octaves and skips the most advantageous position for their execution; in skips letting the hand tilt slightly in the direction of the movement, in octaves holding the wrist slightly raised, the outer fingers gripping the keys with tong-like surety and firmness. As very valuable for octave work he recommended practise of such passages with the wrist held very low, a difficult proceeding, which makes the passage seem many times easier when played afterward in correct position. Tremolo practise he considered of great importance for acquiring strength and endurance.

He himself had a pair of ideal piano hands, short, thick, supple and muscular, the kind that knead the tone out of the keyboard, full, round and luscious. Asked once if large hands were not an advantage in piano playing he replied, "Oh! a man may have big hands and still be a big fool."

In practising his idea was that one must work either for perfection or for endurance. To achieve the former one goes over and over the passage, slowly and carefully, until it is thoroughly learned. Once he said to me smilingly, in regard to a certain arpeggio passage in the first movement of the $G$ major Concerto of Beethoven, "That you must repeat 50,000 times until it is absolutely perfect." In practising for endurance one must play through the entire section of a piece, or the entire exercise or series of exercises, without stopping, no matter how tired one became or what mistakes were made. One must learn to overcome fatigue, must train one's self to be able to carry a 
tiring section through to the end without any outward traces of weariness.

For the technical perfecting of an oft-recurring figure or passage Joseffy recommended taking it in the various keys or transformations in which it might occur during the course of the piece and making a special study of these different forms with disregard (for the time being) of the rest of the composition. He called attention to the advantage of transposing short pieces in the etude style, such as the G major Prelude of Chopin, an excellent technical study for transposition into $G$ flat. Also, he advised the practise with the left hand of some of the Chopin Etudes in which the right hand has difficult passage work in the original, the A minor, op. 10, no. 2, for example, calling attention to the fact that Tausig had followed this proceeding and recommended it to his pupils long before the Godowsky left hand arrangements put in their appearance. In regard to scale practise he recommended a week's work on ordinary scales, followed by a week in which only difficult scale passages from various pieces were studied. Practising without looking at the hands he regarded as a valuable aid for sureness. In difficult arpeggio or passage work he advised a very flexible wrist, moving from side to side as the difficult crossings demanded.

After his pupils had reached a certain degree of development he recommended to them to go abroad for further study, not so much because he considered European teaching superior on the whole to American, but because the pupil should have the advantages offered by European musical life and experience, still immensely superior to those in America. "If a student wants to hear a Mozart opera here in New York, it is impossible for him to do so," he once had occasion to remark regretfully. Not only in the domain of the opera but in practically every other branch of music, excepting purely virtuoso performances, Joseffy recognized the advantage for the talented young musician of musical opportunities in Europe when compared to those offered in America. He did not think very highly of conservatory education, but was rather for study under private teachers of ability and standing.

While he fully knew what an intimate contact with European musical affairs means to the American student, yet he deprecated strongly the general lack of appreciation of native musicians in America. Once he remarked, "It is strange that with all the democratic feeling here, Americans will still run to any foreigner who comes over and advertises a bit. A German or a Russian 
pianist is always somebody, and perhaps we may some day even have a Japanese pianist touring America, for they are so quick to adopt our western civilization. It is only the American product which is not given a fair chance."

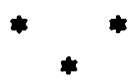

There are probably few modern pianists who have gone into the matter of fingering with such minute detail as Joseffy. With him fingering was almost an art in itself. At the lessons, in his books of technical studies, and in his editions of pianoforte works this matter was always uppermost in his mind. Fingering and tone quality he considered inseparable, the latter depending almost entirely on the former.

He was always a great stickler for niceties in fingering, and the quality of refined elegance which his own playing possessed in so high a degree was doubtless due in a great measure to this characteristic. He was always the gentleman at the piano, and there was a certain exquisite graee in every movement of his hands on the keyboard. Single detached notes in the middle of the instrument he liked to have taken with the second finger, largely on account of the very appearance of the thing, and nothing irritated him more than the amateurish habit of playing single bass notes with any other than the fifth finger, simply to make things easier. He was opposed to any such proceeding as juggling a passage between the two hands, contrary to the original intention of the composer, in order to make the execution less difficult. In fact I cannot recall a single instance either at the lessons or in works of his editing in which he made any such change. When there were technical difficulties he believed in learning to overcome them, and not in trying to get around them through some makeshift or other. There is a cadenza in the Sixth Rhapsody of Liszt which in the original reading for one hand is technically quite difficult, if the requisite cataract of tone is to be developed, but which becomes astonishingly easy of execution through a simple division of the hands, and which is usually so performed. But Joseffy would have none of this sort of thing. "If you cannot play that cadenza with one hand," he would say, "you cannot play the Sixth Rhapsody."

Fingering, he believed, should be made to conform with the average piano hand, although exceptional hands might of course take exceptional fingerings. In practising. he advised the study of single passages with various fingerings, and then the 
selection of the one which fitted itself most naturally into the hand for use when playing. At the lessons be was quite happy when he found that a pupil was making progress in the correct choice of fingerings.

The most clever solutions of difficult problems in fingering always occurred to him, and his re-fingering of an uncomfortable passage often led to the most exquisite perfection in its technical execution. As an example of the cleverness with which he overcame awkward situations, the following illustration from the Larghetto of Chopin's F minor Concerto may be quoted:

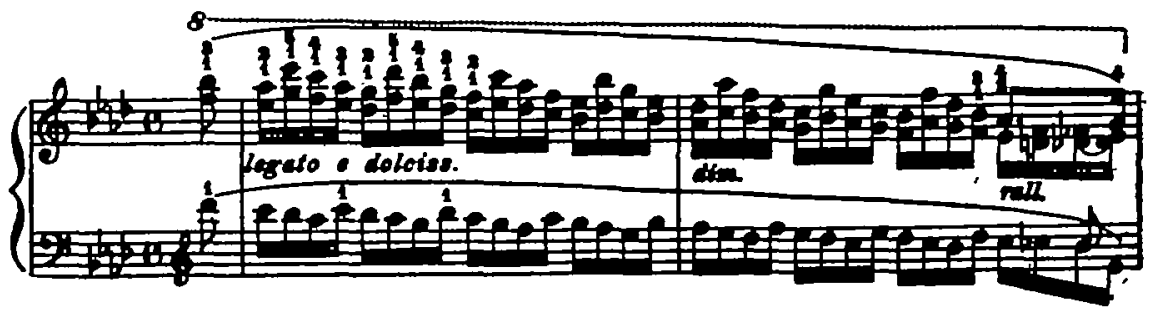

The mere comparison of this ingenious solution with the usual clumsy marking of the passage is sufficient to show the cleverness of Joseffy's ideas in such matters. The following chromatic passage from the Chopin Etude, op. 25, no. 2, fingered after the manner indicated, fits the hand of the pianist like a glove and is typical of the nicety of Joseffy's workmanship:

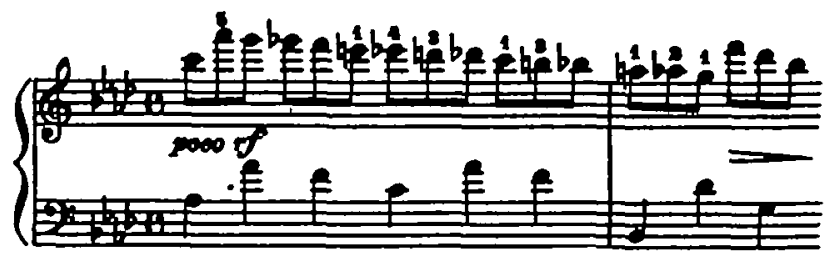

In the selection of study editions for his pupils the matter of fingering always took a position of first importance. Of the Klindworth editions of Chopin and Beethoven he was a great admirer, largely on account of the excellence which he ascribed to Klindworth's manner of fingering, although he was not always in favor of the many liberties which this editor allowed himself in the way of textual emendations, preferring Mikuli's Chopin for accuracy of text. Bulow he thought went a bit too far in some of his notes to the Beethoven sonatas, and he did not consider him very modern in the matter of fingering. "Klindworth has often expressed things of more importance in his mere marks 
of fingering than Bulow in his notes," he said. "With Klindworth no notes are needed; every finger talks." Klindworth he considered a veritable genius at fingering, saying, "As you study Klindworth's Chopin you will always be learning something valuable about fingering. Klindworth is always correct, that is, he always follows out his laws of fingering logically." The Clara Schumann edition of her husband's works Joseffy considered insufficient on account of the lack of marks of fingering, preferring the edition given out by Bischoff as the best makeshift, but not regarding it as an ideal Schumann edition. One of the most excellent things which Joseffy called to my attention in the way of fingering was the Tausig edition of Beethoven's G major Concerto. Here one can really speak of the "art" of fingering, for the editing in this respect is the work of a past master.

Joseffy's own editions of the works of various composers were not the result of a hasty impulse to do something of the sort, but rather the culmination of the study of a lifetime. $\mathrm{He}$ told me once that he had always had it in mind, even during his earlier years, to some time edit the standard works of the pianoforte literature, and to this end he always made copious notes as to fingering, methods of practise and so forth, on all the numbers which he studied for his concert programs. He had an extreme dislike of editors of classical works which had been gone through, fingered and annotated by mediocrities. I remember his remark on seeing an edition of the Schubert-Liszt song transcriptions, to which were attached as editors, the names of two otherwise obscure musical personalities, "X. and Y! Gott, what a combination!" and, "If the publishers want to put out a Lisat edition, why don't they get someone worth while for it, like Busoni," modestly omitting himself.

His great works on technic, the "School of Advanced Piano Playing" and the "First Studies," were also the result of lifelong compilation, connotation and collation of all manners of technical experiments which occurred to him during long years of most painstaking study and most exacting demands on the technical passibilities of the instrument. His "Advanced Piano Playing" he did not expect every one to use. "It is only for very advanced pianists - but for such it is very fine. It may seem a little arrogant for me to say that of my own book, but all pianists who have examined it have admitted it." This was the only thing I remember ever having heard Joseffy say in praise of himself or his works. When anything about himself or his achievements came up in the course of a talk, he always gave the conversation 
a sudden shove in the opposite direction. He had a very small opinion of most of his own piano compositions, and once when I expressed a desire to study something of his he replied, "Oh! I don't know that there is much of anything worth while for you to study. Maybe the Czardas; but I don't like it much myself." He was in fact the most modest of men, having none of the bravado and braggadocio which one is so accustomed to associate with the virtuoso who has conquered the concert audiences of two continents. A mention of the fact that Rosenthal had declared that he owed all his technic to Joseffy was met with a joking depreciation, and in looking over Joseffy's interesting collection of manuscripts and autograph letters, the communication from Liszt in which the latter names Joseffy as his successor and pianistic heir, was passed over in a jiffy: its contents were discovered only afterward through another source.

But in spite of Joseffy's opinion of his own work on technic he often found words of praise for the technical studies of others. "Mason," he said, "has some good ideas in his "Touch and Technic,' and Moszkowski has written a rather remarkable book on double notes, showing that he would make a good pedagogue if he wished." I. Phillip's technical studies he spoke of with appreciation, also of A. K. Virgil's work along this line. Pupils who came to him after studying the Virgil technic he found usually well schooled in this direction, although he regarded the Virgil exercises as studies in "mechanism, not technic." He had a practise clavier and used it often for his own technical work. Of Hugo Mansfeld's book, "New Technic," he said, "Why does he call it "New Technic'? There is nothing new in it." He made this same criticism on most of the modern works on technic, but was quick to approve of a new idea when he recognized it as such.

The "School of Advanced Piano Playing," regarded as a collection of the material necessary for the achievement of the higher technical possibilities of the instrument, stands on the shoulders of all previous collections of technical studies and is certainly the most modern and comprehensive work of the kind in existence. The "First Studies" are rather too diffuse in scope to justify their title, for many of the technical problems therein would put even very advanced pianists on their mettle. The earlier work appears as a happy crystallization of the matter at hand, complete, practical and without redundance; the later volume, while it has the advantages of textual notes, lacking in the earlier book) and thus enables the student to get a clearer idea of the 
author's methods of touch and how to utilize the various exercises in practise, is to a large extent a re-presentation of a great deal of the ground covered in the first work, a new and, on the whole, less successful attempt to solve many of the problems which had already been met and disposed of in such a masterly manner.

The "Advanced Piano Playing" combined such strikingly clever innovations in the way of technical exercises that it would be hardly possible to expect even such an ingenious discoverer along these lines as Joseffy to surpass himself in a second effort. Opening the earlier book at the first page, the "five-finger exercises," the student finds an entirely novel presentation of a timeworn problem, a veritable mountain of technical difficulty in simple guise. The holding of the initial note in the progressing groups of five and the cleverly invented opposition of finger groups to rhythmic groups place these super five-finger exercises in a class quite by themselves.

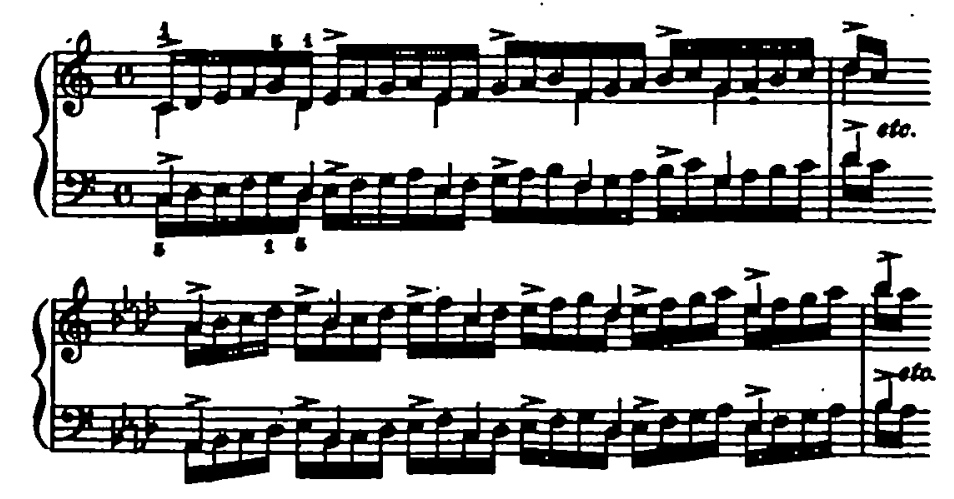

The matter of holding one or more notes while the other fingers are in action has been carried out by Joseffy throughout this work in a most systematic and exhaustive manner, wherever the character of the technical problem makes the process possible, and there can be no doubt that, with the proper precautions against stiffening, this proceeding leads in short order to a high degree of finger strength and independence.

The introductory exercises in thirds exhibit a new idea in the practise of double notes; I have seen in it no previous work on technic. I speak of the following ingenious arrangement, in which of course the voices may also be reversed, and which may be used not only for thirds, but for sixths and all sorts of other double-note combinations. 


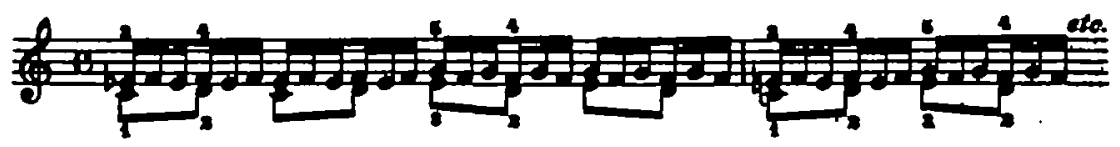

In the octave exercises, the stress laid on the strengthening of the outer fingers before the wrist movements are taken up, is of the utmost importance, for fully as much bad octave playing comes from the inability of the player to achieve absolute, unyielding firmness in the position of the hand as from lack of strength and suppleness in forearm and wrist.

The exercises in various kinds of touch in both the books are, many of them, unique, and demand the highest degree of independence, not only between the two hands, but between the different parts of each separate hand. The same may be said of the rhythmic studies, of which those in the "Advanced Piano Playing" are by far the more elaborate and valuable. The exercises for the thumb and little finger, of which excellent examples are found in both books, including some even with the thumb on two keys, are novel and important, and the studies for changing fingers on one key quite exhaust the possibilities of the subject.

Joseffy's method of practising the glissando is one that will be appreciated by all those players who on account of weakness in the hand, thin fingers or sensitive finger tips find such passages difficult. One begins by skimming the surface of the keyboard lightly with the bent finger, allowing only the nail to touch the keys, gradually adding more weight each time until finally the tone comes, very softly at first, then fuller and quite full in quality as more pressure is added. The practise of the glissanto is something that at all events should be gingerly indulged in and not carried to the extent of sore and perhaps bleeding finger tips. It is a historical legacy of piano playing, however, and as such the modern pianist must be familiar with its execution. Besides its occurence in the works of Beethoven, Weber and Lisst, it is found even in the compositions of such an opponent of a purely virtuoso treatment of the instrument as Brahms.

Among the exercises in the "First Studies" which are both original and important are those dealing with sureness in large skips, accompaniment figures for the left hand alone and the training of the eye to watch different parts of the hand while playing. The fact that it is an exceedingly difficult matter to play an octave passage, for example, looking at the fifth finger instead of the thumb, unless one has made this a matter of special practise, was first called to my attention by Joseffy. Anyone who 
has never made this experiment at the keyboard will probably be very much surprised at its awkwardness when first attempted.

In all these studies there is the indubitable evidence of the musician as distinguished from the mere maker of exercises, at every point where the solution of the technical problem makes at all possible the appearance of the fine hand of the artist. This is one of the chief claims to their exalted position among works of the kind. The "Advanced Piano Playing" in particular is so full of clever inventions that there is a refreshing lack of dryness about the whole. There are few artists of Joseffy's rank who have been interested enough in the technical side of piano playing to have busied themselves to such an extent and with such success as he did, with mere technical matters, without at the same time losing to some extent their grip on the purely musical side of the art, as they have acquired more interest and adroitness in keyboard jugglery. With him the "how," all important as it is to the reproductive artist, was, at the end, always servant to the "what," and although the very manner of his playing in itself often reached those heights which great virtuosi sometimes attain, where the performance itself is of such marvellous beauty that it seems to transcend entirely the subject matter of the composition, his art was not of the sort which deliberately aims at such a result. A mere virtuoso would never have given himself up to the pioneer work of making propaganda for Brahms' piano compositions at the time and with the loving enthusiasm that Joseffy did.

It is a good deal of a pity, from the student's point of view, that the "Advanced Piano Playing" is so absolutely devoid of text, that discussions of method and directions for practise are almost completely lacking. In the "First Studies" Joseffy evidently started out with the firm intention of "making good" this matter, and although he succeeded in a measure, the text is, as a whole, quite insufficient; all too many important matters are left completely untouched. Perhaps in future editions of the works this hiatus may be bridged over through the aid of some editor who is intimately familiar with the author's aims and thoroughly in sympathy with his ideals.

It may be said in general that Joseffy recommended practising many of his own studies, as well as difficult passages in pieces and études with various qualities of touch, first with normally raised fingers, then with high fingers, with the pressure touch, finger staccato, wrist staccato, using both high and low wrist, 


\section{Rafael Joseffy's Contribution to Piano Technic $\mathbf{3 6 3}$}

and finally with the normal finger touch again, employing various degrees of power for the several repetitions and making use also of the crescendo and diminuendo. Above all he required that the fingering of his studies be adhered to with extreme care, the technical value of the exercises depending largely on their being practised with the fingering marked. He was extremely particular about rests and accents, insisting upon great accuracy in these matters. Although he mentioned the fact that no grest pianist has practised with the metronome, he realized the importance of this instrument in technical work for the large majority of students and recommended its use to grade progress in velocity.

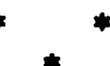

As a whole Joseffy's attitude towards the development of technic may be regarded as conservative. He would never have recommended any such unconventionalities, for example, as that of using the thumb doubled up against the fist to produce a particularly strong accent; he would have met such a contingency by inventing exercises with the specific object of strengthening the thumb to the point where it would be able to master the situation in its normal relation to the keyboard. He established for himself certain principles of technical procedure, and he believed in applying them to all circumstances. If they proved seemingly insufficient in some cases, it was the fault of the imperfection of the individual technical apparatus, and not of the principles. Although, in view of the most modern developments in piano playing, his mode of procedure, his method, may seem to some a trifle oldfashioned, this cannot be conceded to imply criticism of the material for technical development which he has left us in his two books of studies. As to the originality and cleverness in the presentation of the subject matter, the wealth of new ideas and the completeness of material which these two volumes exhibit, there is little room for cavil.

Joseffy's own playing underwent a marked change during the years following his coming to America. Those who heard him in the earlier part of his career describe the dainty elegance of his performances, the wonderful grace and the unequalled technical perfection of his style. They gained for him the sobriquet of the "Patti of the piano." But Joseffy soon lost his taste for mere miniature at the keyboard; he joined the modern movement whose ideal lay in the direction of big tone and big piano playing. After a period of self-immolation spent in perfecting his new 
manner, he surprised his former admirers by appearing now as one of the very Titans of the instrument, at the same time retaining the delicacy and charm of his older style. Wilhelm Gericke once said to me in Vienna, speaking of Joseffy's performance of the Rubinstein D minor Concerto with the Boston Symphony Orchestra under his leadership, "His tone was so enormous and there was such a broad sweep to his playing that it seemed like a veritable re-incarnation of Rubinstein himself."

In speaking of the younger generation of pianists Joseffy once said, "There are so many young pianists now-a-days, all of whom have fine technic, that only those who are very exceptionally gifted can hope to shine by technical superiority. It seems to me that they must aim at more musicianship now, instead of at so much technic. And what programs they play! Who wants to hear nothing but little things and show pieces? One must play the big things."

And so with all the loving care with which he worked at his technical problems, filing, polishing, refining, all this was merely labor along the highway. His eye was ever fixed on the far-off goal, the perfect blending of eminent virtuosity with equally eminent musicianship.

Joseffy lived so long in America and did so much of his most important work among us that we are quite justified in thinking of him affectionately as "our Joseffy." Although occesionally the feeling came over him that he might find a broader field for the unfolding of his activities in one of the German art centers, it never grew so strong as to induce him to break the ties which held him to New York, and he remained a good American to the very end. On his last visit to Europe, during the summer of 1913, he was on pins and needles the whole time to get back to his work and his own congenial surroundings in America, and this matter contributed very probably to the causes of the nervous breakdown which he suffered after his return. His entire interest and activity were centered in the development of his sphere of musical art in America. May the influence of his refined artistry and of his high ideals be felt for many years to come. Among those whose opportunity it was to come into more intimate contact with Rafael Joseffy, the sincere artist and generoushearted friend will remain an ever fresh memory. 